\title{
Development of a cDNA microarray for the measurement of gene expression in the sheep scab mite Psoroptes ovis
}

Stewart TG Burgess ${ }^{1 *}$, Alison Downing ${ }^{2}$, Craig A Watkins ${ }^{1}$, Edward J Marr ${ }^{1}$, Alasdair J Nisbet ${ }^{1}$, Fiona Kenyon ${ }^{1}$, Carol McNair ${ }^{3}$ and John F Huntley ${ }^{1}$

\begin{abstract}
Background: Sheep scab is caused by the ectoparasitic mite Psoroptes ovis which initiates a profound cutaneous inflammatory response, leading to the development of the skin lesions which are characteristic of the disease. Existing control strategies rely upon injectable endectocides and acaricidal dips but concerns over residues, ecotoxicity and the development of acaricide resistance limit the sustainability of this approach. In order to identify alternative means of disease control, a deeper understanding of both the parasite and its interaction with the host are required.
\end{abstract}

Methods: Herein we describe the development and utilisation of an annotated $P$. ovis CDNA microarray containing 3,456 elements for the measurement of gene expression in this economically important ectoparasite. The array consists of 981 P. ovis EST sequences printed in triplicate along with 513 control elements. Array performance was validated through the analysis of gene expression differences between fed and starved $P$. ovis mites.

Results: Sequences represented on the array include homologues of major house dust mite allergens and tick salivary proteins, along with factors potentially involved in mite reproduction and xenobiotic metabolism. In order to validate the performance of this unique resource under biological conditions we used the array to analyse gene expression differences between fed and starved $P$. ovis mites. These analyses identified a number of house dust mite allergen homologues up-regulated in fed mites and $P$. ovis transcripts involved in stress responses, autophagy and chemosensory perception up-regulated in starved mites.

Conclusion: The P. ovis cDNA microarray described here has been shown to be both robust and reproducible and will enable future studies to analyse gene expression in this important ectoparasite.

Keywords: Psoroptes, sheep, microarray, gene, expression

\section{Background}

Sheep scab, a highly contagious disease caused by the mite Psoroptes ovis, is characterised by pruritis and irritation of host skin and is therefore a major welfare concern in addition to the substantial costs associated with lost performance, preventative measures, and treatment $[1,2]$. Current disease control strategies are heavily reliant upon injectable endectocides and acaricidal dips but concerns over residues, environmental contamination

\footnotetext{
* Correspondence: stewart.burgess@moredun.ac.uk

'Moredun Research Institute, Pentlands Science Park, Bush Loan, Edinburgh. Midlothian. EH26 OPZ. UK

Full list of author information is available at the end of the article
}

and the development of acaricide resistance limit the sustainability of this approach and have resulted in growing interest in the development of alternative control methods [3]. The development of such methods requires a more detailed understanding of both the parasite and its interaction with the host.

The basic biology of the mite is well understood: The entire life cycle of $P$. ovis is carried out on the ovine host and takes from 11-19 days from egg hatch to egg production by the adult [4]. Mites can survive off-host, enabling their transfer from animal to animal; however, they only remain infective for 15-16 days once removed from the skin [5]. P. ovis is a non-burrowing, surface 
exudate feeder capable of consuming serous fluids, lymph and red blood cells [6]. Mites survive on the surface of the skin and their mouthparts, which are thought to abrade rather than pierce the skin, do not penetrate beyond the stratum corneum, the outermost layer of the skin [7]. The available evidence suggests that mites abrade the stratum corneum and deposit allergens as they progress. The combination of mechanical skin abrasion, mite allergen deposition and grooming behaviour by the host in response to the pruritis caused by the mites triggers the subsequent activation of a cutaneous inflammatory response $[8,9]$ including an exudate which has been proposed to supply the mite with a food source [10]. Establishment of a $P$. ovis infestation is therefore the result of a complex interaction between the host and the mite, during which the mite appears to initiate reactions conducive to its own establishment and maintenance [11]. The skin lesions are induced by mite-derived pro-inflammatory factors, a likely source of which are mite excretory/secretory products, including potent enzymes and allergens (reviewed in [10]). While several mite products have been identified, including enzymes and homologues of allergens of the house dust mite (HDM), Dermatophagoides pteronyssinus and the scabies mite Sarcoptes scabiei, their functions in disease progression remain largely unknown [12].

In the host, a major histological feature of sheep scab is the rapid (within 24 hours) epidermal influx of eosinophils and neutrophils, followed by blister formation and a pronounced serous fluid exudate resulting in dermal oedema [13]. Prior infestation with sheep scab mites alters the progression of subsequent infestations and reductions in lesion size have been observed in secondary infestations in sheep [14]. This evidence points to the development of a protective immune response to $P$. ovis in sheep and offers encouragement for control by vaccination [3]. Vaccination with fractionated $P$. ovis soluble extracts has resulted in a 15 -fold reduction in mite numbers and a 4-fold reduction in lesion size $[15,16]$. However, identification of the individual proteins involved in the development of this partially protective immunity has not yet been achieved. To further understand the mite:host interaction and identify suitable avenues for the discovery of novel interventions we have previously generated a $P$. ovis cDNA library and undertaken an expressed sequence tag (EST) approach [17]. This paper describes the use of these ESTs in the construction of a P. ovis cDNA microarray and the utilisation of this array, the first resource of its type for this economically important ectoparasite, under biological conditions to analyse mite gene expression during exposure to, and removal from, the host. This approach was used to analyse which mite genes were expressed at enhanced levels during critical events in the host parasite relationship, for example mite feeding and digestion - processes which are vital to parasite survival.

\section{Methods \\ Psoroptes ovis mite collection}

Ethical approval for this study was obtained from the Moredun Research Institute Experiments Committee. $P$. ovis mites (a mixed population consisting of adults, nymphs and larvae) were harvested from infested donor animals maintained at the Moredun Research Institute as previously described [8]. For the construction of the $P$. ovis cDNA library $\sim 800 \mathrm{mg}$ of live mites were snap frozen in liquid nitrogen and stored at $-80^{\circ} \mathrm{C}$ for subsequent RNA extraction. This stock of $P$. ovis mite RNA was used in the construction of the mite cDNA library and also represented the "fed" mite sample. "Starved" mites were obtained by following the same procedure as above, except that, following harvesting, mites $(\sim 100$ $\mathrm{mg}$ ) were placed into a $75 \mathrm{~cm}^{2}$ vented cap cell culture flask (Corning, UK) and incubated for 4 days at $25^{\circ} \mathrm{C}$ with $80-90 \%$ relative humidity.

\section{Extraction of total RNA from $P$. ovis}

Total RNA was isolated from mites as described previously [18]. RNA samples were further purified using a Qiagen RNeasy kit, following the manufacturer's RNA cleanup protocol and on-column DNase I digestion for 15 minutes at room temperature, before elution into RNase free $\mathrm{dH}_{2} \mathrm{O}$. Total RNA yield was assessed using a Nanodrop spectrophotometer and RNA quality was assessed using an Agilent Bioanalyser (Agilent, UK).

\section{Construction and sequencing of a $P$. ovis mite cDNA library}

A normalised $P$. ovis cDNA library was constructed by Eurofins MWG, Germany from total RNA extracted as above. The cloning vector used was pBluescript II sk+ and the primary library titre was estimated to be $1,150 \mathrm{cfu} / \mu \mathrm{l}$; the total number of clones was estimated to be 2.3 million and the average insert size was $\sim 0.9 \mathrm{~kb}$. Normalisation was carried out by denaturation and subsequent reassociation of the cDNA strands. Nucleotide sequence was obtained from 1574 randomly selected clones (Eurofins MWG, Germany). ESTs with an overlap of $>50$ bp were assembled into 165 contiguous sequences (contigs) while the remaining 1,091 ESTs remained as singletons. ESTs were filtered to remove poor quality sequences (EST length $<100 \mathrm{bp}$ ), to remove vector and adaptor sequence and to mask polyA tails. In order to identify homologues of the assembled $P$. ovis EST sequences, all singletons and contigs were BLAST searched against the Genbank nonredundant nucleotide and amino acid databases using BLASTn and BLASTx, respectively [19]. Sequences with homologue descriptions containing the keywords 
ribosomal, tRNA, mitochondrial and Escherichia coli were removed, leaving 1,033 ESTs for subsequent polymerase chain reaction (PCR) amplification.

\section{Amplification of cloned $P$. ovis cDNAs}

$P$. ovis amplicons, representing the EST sequences $(\mathrm{n}=$ 1,033) described above were amplified by PCR using vector-specific oligonucleotide primers in the following reaction for each 384 well plate ( 3 plates in total used): $168 \mu \mathrm{l}$ FastStart Taq polymerase (Roche, UK); 15,378 $\mu \mathrm{l}$

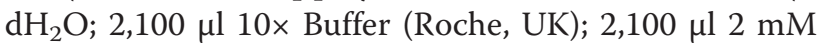
dNTPs (Roche, UK); 1,260 $\mu 125$ mM MgCl (Roche, UK); $42 \mu \mathrm{l}$ BSKS F primer $(100 \mathrm{pmol} / \mu \mathrm{l})$ and $42 \mu \mathrm{l}$ BSKS R primer (100 pmol/ $\mu \mathrm{l}$ ) (ARK Genomics, UK) for a total PCR reaction volume of $50 \mu \mathrm{l}$ per well (reactions carried out in 96-well plates). PCR amplification was performed in a Dyad PCR machine (MJ Research, UK) and started with incubation at $95^{\circ} \mathrm{C}$ for 6 mins followed by 15 cycles of $95^{\circ} \mathrm{C}$ for 30 secs; $58^{\circ} \mathrm{C}$ for 30 secs and $72^{\circ} \mathrm{C}$ for $1 \mathrm{~min}$. Amplification then progressed for a further 19 cycles with the same conditions except that the $72^{\circ} \mathrm{C}$ product extension phase was extended by 5 seconds after each cycle. PCR amplification was concluded with $7 \mathrm{~min}$ incubation at $72^{\circ} \mathrm{C}$. PCR product cleanup was performed using a Sciclone Liquid Handling System (Caliper, UK). Each $50 \mu \mathrm{l}$ PCR reaction was filtered through a 384-well PCR filter plate (Millipore, UK) using positive head pressure for $10 \mathrm{mins}$, washed with $100 \mu \mathrm{l}$ of MilliQ water and positive pressure applied for a further 10 minutes. Forty microlitres of $\mathrm{dH}_{2} \mathrm{O}$ was added to each well and mixed with shaking for 10 mins, samples were then aspirated with mixing and transferred to a 384-well cleanup plate (Genetix, UK). Successful PCR product amplification was assessed by the presence of a single product band through gel electrophoresis; $2 \mu \mathrm{l}$ PCR product was mixed with $7 \mu \mathrm{l}$ TE/glycerol (2:1) mix and $5 \mu$ l loaded onto a $1 \%$ agarose gel. PCR amplification yield was assessed using a Fluoroskan Ascent microplate fluorometer (Thermo Fisher, UK). Briefly, PCR product concentration was assessed by adding $20 \mu \mathrm{l}$ of a 1:200 dilution in TE of each cleaned PCR product into a 384-well Fluorotrac plate (Greiner, UK) along with $20 \mu$ l Picogreen solution (Thermo Fisher, UK) and DNA concentration determined by comparison to a standard curve. Fifty two of the 1,033 EST sequences failed to sufficiently amplify either a single PCR product or a sufficient yield of product for printing and were therefore excluded from the microarray generation, leaving 981 ESTs represented on the $P$. ovis cDNA microarray.

\section{EST annotation}

The $981 P$. ovis ESTs used for printing the cDNA microarray were annotated by homology comparison employing the NCBI non-redundant (nr) database using the NCBI BLASTn function within the blast2go software package [20-22]. Where available, Gene Ontology (GO) annotation was also associated with each probe from within the blast2go package. This process and the annotated dataset has been published previously [17] and annotation of the $P$. ovis cDNA microarray is available in Additional File 1.

\section{Construction of the $P$. ovis CDNA microarray}

In order to obtain representative data for the relative expression of each probe and reduce overall variation, all EST probes were printed onto the arrays in triplicate. To aid data analysis and interpretation, a number of standard control probes were also printed, including Landing Lights for array alignment, salmon sperm DNA, Cot-1 DNA, $P$. ovis and murine genomic DNA probes and a range of positive and negative spike-in control probes (Alien Spot Report, Stratagene, UK). Both positive and negative control probes were printed onto the array in a minimum of triplicate. Array printing was performed on a Super Marathon microarray Inkjet printer (Arrayjet, UK) using a 32 JetSpyder to pick up DNA samples from the plate and transfer to the inkjet print head. Slides used were GAPSII (Corning, UK). All test probes were printed at $115 \mathrm{ng} / \mu \mathrm{l}$ using a print volume of $14 \mu \mathrm{l}$. Alien Spot Report probes were printed at either $100 \mathrm{ng} / \mu \mathrm{l}$ or in a dilution series of 8 spots $(100 \mathrm{ng} / \mu \mathrm{l}-10 \mathrm{fg} / \mu \mathrm{l})$. Human Cot-1 DNA and Salmon Sperm DNA controls were printed at $50 \mathrm{ng} / \mu \mathrm{l}$, polyA control probe was printed at 5 ng/ $\mu$ l whilst $P$. ovis and murine genomic DNA were printed at $150 \mathrm{ng} / \mu \mathrm{l}$. After printing, slides were baked at $80^{\circ} \mathrm{C}$ for 4 hours to allow covalent bond formation, fixing the cDNA to the slide. Slides were then blocked with bovine serum albumin (BSA, $0.1 \mathrm{mg} / \mathrm{ml}$ in $\mathrm{dH}_{2} \mathrm{O}$ ) at $42^{\circ} \mathrm{C}$ for 1 hour to prevent non-specific binding.

Arrays were printed, four on each slide, to fit within the confines of the MAUI (A4 mixer) $4 \times$ hybridisation cassette (BioMicro Systems, USA) allowing 4 arrays to be run on a single slide. Each array consisted of 3 replicate blocks of $36 \times 32$, arranged 12 blocks per slide for the 4 arrays. Each slide contained a total of 13,824 probes, with each of the 4 arrays consisting of 3,456 probes. This was broken down into 2,943 P. ovis probes (981 ESTs printed in triplicate) and 513 control elements which included 15 positional controls with 5 probes per block [Landing Lights, Alien Spot Report (Stratagene, UK) PCR product 1], 9 P. ovis genomic DNA (gDNA) probes, 9 mouse gDNA probes, 3 polyA control probes, 3 Salmon Sperm DNA control probes, 3 cot-1 DNA probes, 330 spotting buffer probes, 96 positive spike-in controls printed as 4 sets of 8 probes in a dilution series in triplicate (Alien Spot Report PCR products 7-10) and 45 negative spike-in controls printed as 
5 sets of 9 probes (Alien Spot Report PCR products 2$6)$. The $P$. ovis cDNA microarray and the associated GAL file have been submitted to the ArrayExpress database and are accessible under the following accession number: A-MEXP-2063, with the title: Psoroptes ovis cDNA microarray.

\section{Microarray quality control}

To limit the degree of slide to slide variation for array analysis, the $P$. ovis cDNA arrays were printed in a single print run. Array print quality was checked by randomly selecting 4 microarray slides from across the print run and hybridising with Panomer-9 oligonucleotides to visualise both the shape and size of all printed spots, ensuring uniformity in the amount of DNA spotted. This analysis confirmed that the microarray printing was of a consistent and acceptable quality (Data not shown).

\section{RNA preparation, labelling and amplification}

Linearly amplified RNA (aRNA) was generated from 100 ng total RNA of each sample for analysis using the MessageAmp aRNA kit (Ambion, UK) according to the manufacturer's instructions. The aRNA was indirectly coupled with a fluorescent $\mathrm{Cy}$ dye, either $\mathrm{Cy} 3$ or $\mathrm{Cy} 5$ (GE Bioscience, UK) by the incorporation of a 5-(3-aminoallyl)-UTP in a cDNA synthesis reaction, followed by dye binding and purification following the protocol available on the ARK Genomics website (http://www. ark-genomics.org/protocols/DyeCouplingAaRNA.php).

\section{Microarray hybridisation and washing}

Hybridisations were performed on a MAUI microarray hybridisation system (BioMicro Systems, USA) using the MAUI Mixer A4 hybridisation cassette with a $16 \mu \mathrm{l}$ fill volume per chamber (BioMicro Systems, USA) which allowed the four microarrays on a single slide to be treated independently. The hybridisation mixture consisted of the following: $13.6 \mu \mathrm{l}$ of a 1:1 mixture of UltraHyb (Ambion, UK) and $2 \times$ SSC (Sigma, UK); $1.6 \mu$ l PolyA (10 mg/ml, Sigma, UK); $1.6 \mu \mathrm{l}$ of $25 \mathrm{pmol}$ Cy3 labelled sample; $1.6 \mu \mathrm{l}$ of 25 pmol Cy5 labelled samples; $0.8 \mu \mathrm{l}$ Salmon Sperm DNA (10 mg/ml, Invitrogen, UK) and $0.8 \mu \mathrm{l} \mathrm{BSA}(50 \mathrm{mg} / \mathrm{ml}$, Ambion, UK) to a final volume of $20 \mu \mathrm{l}$. Hybridisation was performed at $42^{\circ} \mathrm{C}$ for 16 hours in a microarray hybridisation oven (Agilent Technologies, UK). Slides were washed by dipping up and down for $1 \mathrm{~min}$ in Buffer $1(0.2 \times \mathrm{SSC}+0.5 \% \mathrm{SDS})$ and then for one min in Buffer $2(0.2 \times$ SSC). Slides were then placed into slide racks with lint free tissue at the bottom, and centrifuged at 1,200 rpm for 6 mins to dry.

\section{Microarray scanning, data extraction and data analysis}

Slides were scanned on an Axon 4200AL microarray scanner (Molecular Devices, UK) with laser power set at
$80 \%$. The optimum fluorescent signal with limited saturation was selected using the Auto PMT setting. Data extraction was performed within GenePix Pro (Version 7, Molecular Devices) for each individual array using the GenePix Array List (GAL) file. Data analysis was performed using the Partek Genomics Suite (Partek Inc, USA). Dye swaps were performed for all of the array comparisons and raw microarray data for each array were normalised using the default RMA function within the software and differential expression of transcripts represented by the probes determined using the one way analysis of variance (ANOVA) function. The batch effect ANOVA function of Partek was run to remove the effect of dye from the results. Multiple test correction was performed using the Benjamini \& Hochberg False Discovery Rate (FDR) procedure with an FDR corrected p-value cut-off of $\leq 0.05$ [23].

\section{Scatter plot analysis of microarray performance}

In order to determine the ability of the array to detect differences in gene expression under experimental conditions a range of hybridisations were performed comparing control (fed P. ovis RNA) and biological (starved and fed $P$. ovis RNA) samples. Scatter plots were prepared using the raw non-normalised, transformed (natural log) array data, averaged for each comparison from the four hybridisations (2 dye-swapped (Cy3/Cy5) replicates each) and linear regression analysis performed to determine the degree of variance between the individual comparisons using GraphPad Prism (GraphPad Software Inc, Version 5.04).

\section{Quantitative real-time PCR (qPCR) analysis of selected microarray probes}

qPCR analysis was performed on the original RNA samples used to generate the aRNA employed in the microarray studies, i.e. control (fed) P. ovis and starved P. ovis mite RNA. Two differentially expressed candidate genes from the fed vs starved $P$. ovis microarray comparison were selected for further analysis by qPCR, namely Pso o 1 and Pso o 2. Gene specific primers were designed based on the $P$. ovis sequence data for Pso o 1 and Pso o 2 using the Primer3 program [24]. Primer sequences were as follows: Pso o 1-Forward (5'TCAAGCTTGCCAAATCGGCGC'3), Pso o 1-Reverse (5'CACCACCGCAACCGTGTTGTG'3), Pso o 2-Forward (5'AGGCTG TTCAGGTGATTACTGCGT'3), Pso o 2-Reverse (5'TGGCAACCATCATGATCACGCCA'3). Relative quantification of gene expression was performed using the standard curve method and data was normalised to the level of a housekeeping gene $[P$. ovis beta-actin, primer sequences as follows: beta-actin-Forward (5'TGAATTGCCTGATGGTCAAG'3), beta-actinReverse (5'TGGCGAACAAGTCTTTACGG'3)]. First 
strand cDNA was synthesised from $100 \mathrm{ng}$ of the $P$. ovis aRNA samples using Superscript II (Invitrogen, UK) and oligo(dT) primers (Sigma-Aldrich, UK) according to manufacturer's instructions. qPCR was performed in quadruplicate on cDNA samples using an ABI Prism 7000 real-time thermal cycler (Applied Biosystems, UK) and the primer sets as defined above. Standard curves were constructed from serial 10-fold dilutions $\left(10^{8}-10^{2}\right.$ copies per $\mu \mathrm{l}$ ) of previously constructed and linearised plasmids containing the relevant $P$. ovis gene (Pso o 1 , Pso o 2 or beta-actin) and amplified in parallel with each series of samples allowing the automatic generation of standard curves using the Applied Biosystems 7000 System SDS software. Correlation co-efficients of the standard curves were between 0.97-0.99 and PCR efficiencies calculated from the slopes were $\geq 90 \%$. The number of copies per microlitre of cDNA was calculated and the results normalised to that of $P$. ovis beta-actin.

\section{Results}

Microarray construction and gene products represented on the microarray

The most abundant phylum associated with the top BLAST hits for the ESTs used in the construction of the array was the arthropoda, with the most common representative species being the deer tick, Ixodes scapularis (172 ESTs or $18 \%$ of the total with significant BLAST hits). This probably reflects the observation that I. scapularis represents the most closely related species to $P$. ovis with an annotated genome. In addition, a number of ESTs shared homology with gene products from the closely related HDMs D. pteronyssinus (10 ESTs) and D. farinae (8 ESTs), including homologues of mite allergens, i.e. Der p 1, Der p 2, Der p 3 and Der p 21. Annotation of the $P$. ovis cDNA microarray can be seen in Additional File 1.

\section{Gene ontology (GO) annotation of the microarray}

The sequences of the probes on the array cover a total of 3,509 individual GO terms and GO term annotation showed that 644 of the 981 microarray probes (67\%) were associated with at least $1 \mathrm{GO}$ term, with 89 probes being associated with $>10 \mathrm{GO}$ terms. These GO associations can be broken down into the major categories of biological process (43\%), molecular function (31\%) and cellular component (26\%). All EST sequences represented on the array have been submitted to GenBank and the relevant accession numbers associated with each probe are denoted in Additional File 1. In addition the full GO annotation of the $P$. ovis ESTs used for the construction of the cDNA microarray has been published previously [17].

\section{Microarray performance}

To assess the performance of the array the following dye-swapped hybridisation comparisons were set up: A.
Self (fed P. ovis) vs self (fed P. ovis), B. Biological replicates (replicated analysis of fed $P$. ovis control $v s$ starved $P$. ovis, compared using two separate dye swapped arrays), C. Activated biological sample (starved $P$. ovis) vs control sample (fed $P$. ovis). Scatter plots demonstrating the degree of variance between each of these comparisons can be seen in Figure 1. These demonstrate the high degree of correlation between the self $v s$ self hybridisations $\left(R^{2}=0.9709\right)$ and between replicate samples $\left(R^{2}=0.9786\right)$, whilst also showing the increased level of variation within the biological comparison, i.e. fed $P$. ovis vs starved $P$. ovis mites $\left(\mathrm{R}^{2}=0.8920\right)$.

\section{Experimental Design}

Array performance on biological samples was assessed through the comparison of RNA from "fed" P. ovis mites compared with RNA from $P$. ovis mites, which had been "starved" for 4 days. Samples were prepared as described above and analysed in duplicate with dye swapped (Cy3/Cy5) samples included, i.e. four hybridisations each.

\section{Fed vs starved $P$. ovis comparison}

Based on the parameters described above (FDR $\leq 0.05$ and $F C \geq 1.5$ ) a total of 684 probes represented transcripts which were differentially expressed between the fed and starved $P$. ovis mite samples. Nine of these probes represented transcripts which were present at higher levels in the fed mites (FC range from 1.51 2.47) whilst the remaining 675 probes represented transcripts which were present at lower levels in fed mites (i.e. higher levels in starved mites) FC range 1.5 - 2.68.

\section{Fed $P$. ovis - enriched transcripts}

Transcripts present at higher levels in the fed mites included well-characterised mite allergens; the cysteine protease Pso o $1(\mathrm{FC}=2.17)$, the gut associated factor Pso o $2(\mathrm{FC}=2.15)$ and a $P$. ovis homologue of the HDM group 21 allergen (Der p 21), termed here Pso o 21 (FC = 1.83). The full list of transcripts found to be up-regulated in the fed $P$. ovis mite sample can be seen in Table 1.

\section{Starved $P$. ovis - enriched transcripts}

Among transcripts present at higher levels in the starved mites were homologues of those encoding five heat shock proteins, three of which were homologues of putative proteins from the deer tick, I. scapularis. We also observed the 2-fold up-regulation of a homologue of the receptor (chemosensory) transporting protein from $I$. scapularis and receptor accessory protein 4 from Caenorhabditis briggsae in starved P. ovis mites. Homologues of two genes with roles in autophagy [autophagy related homologue 3 (ATG3) and DNA-damage 


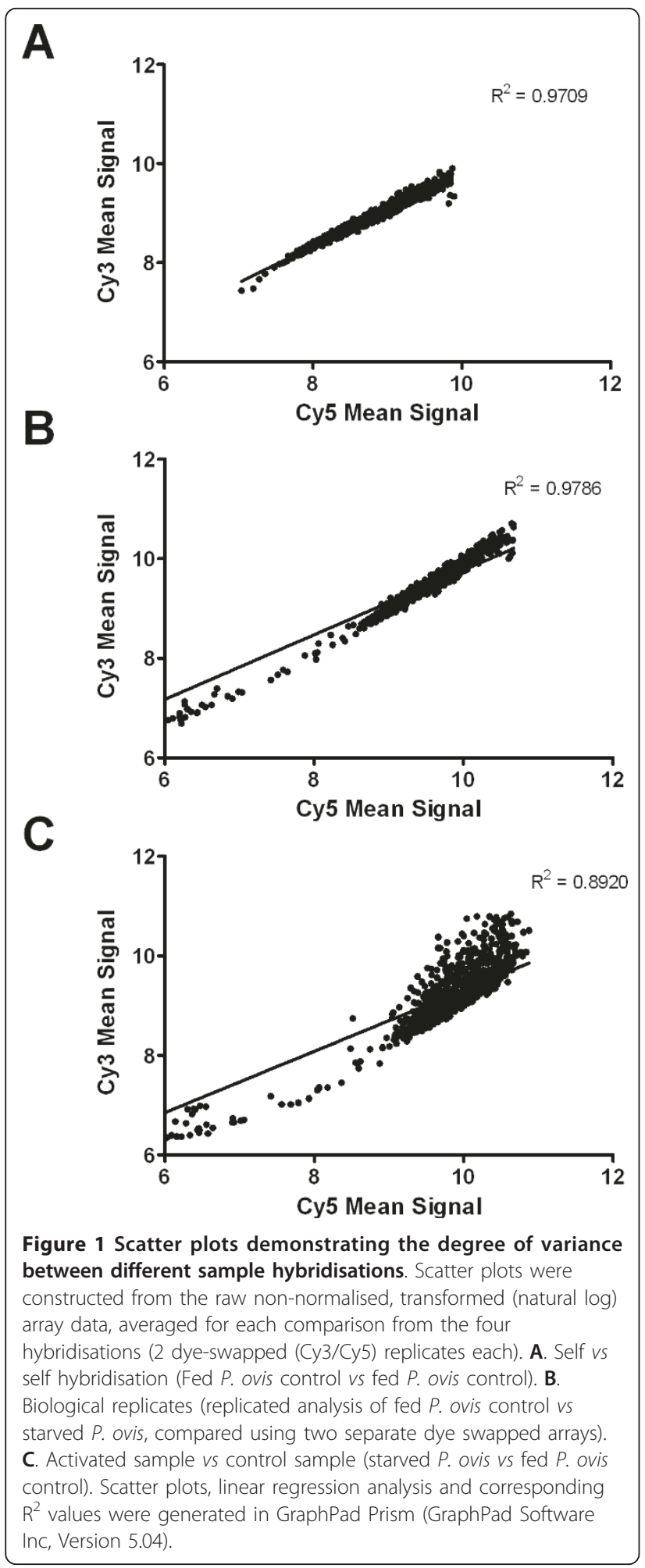

regulated autophagy modulator 1 (DRAM1)] also showed 2-fold up-regulation in the starved mites. The top 20 transcripts (highest fold change) up-regulated in the starved $P$. ovis mite sample can be seen in Table 2 and the full list of 675 probes is available in Additional File 2.

\section{qPCR analysis of selected microarray probes}

The differential expression of two selected genes (Pso o 1 and Pso o 2) between fed and starved P. ovis mites was verified using $\mathrm{qPCR}$, which confirmed the up-regulation of both genes in fed P. ovis mites. The microarray data highlighted an approximate 2-fold up-regulation of both Pso o 1 and Pso o 2 in fed P. ovis mites and the qPCR results for these genes further supported these findings with the up-regulation of both genes being confirmed. The magnitude of change in the level of Pso o 2 was very similar between the two techniques, with a 3.1fold change seen in the qPCR (compared to 2.15-fold with the microarray), whilst the magnitude of the change in Pso o 1 was higher with the qPCR at 9.6-fold (compared to 2.17-fold with the microarray). Therefore, this analysis demonstrated a good degree of agreement between the qPCR and mite cDNA array data between fed $v s$ starved $P$. ovis mites.

\section{Discussion}

Here we have described the development, construction and utilisation of a cDNA microarray based on the currently available ESTs for the economically important ectoparasite, $P$. ovis. This currently represents the most extensive transcriptomic resource for the analysis of this parasite. The $P$. ovis probes on the microarray were derived from a mixed population of mites including larvae, nymphs, and male and ovigerous female adults. As such these are likely to represent a broad range of expressed genes across all $P$. ovis life cycle stages, producing an array that is applicable to a range of different analyses. Sufficient controls were included in the array design to ensure effective normalisation and all of the EST probes were printed in triplicate enabling an accurate estimation of gene expression. The content of the array, although limited to the currently available $P$. ovis ESTs, includes homologues of HDM allergens and probes for a number of other important mite factors, i.e. proteolytic enzymes, homologues of tick salivary factors, heat shock proteins and factors involved in drug and xenobiotic metabolism [17]. In addition, the array contains factors with no significant homology from BLAST searching which may represent novel $P$. ovis transcripts and thus provides the opportunity for novel discoveries into the underlying biology of the mite.

By using this microarray to analyse the expression of suites of genes relating to a fundamental feature of host: parasite interaction and mite biology (i.e. feeding), we are moving towards the rational selection of molecular targets for parasite intervention - the identification of vaccine candidates by a "rational" approach. This 
Table 1 Transcripts significantly up-regulated in the fed $P$.ovis mite sample

\begin{tabular}{|c|c|c|c|c|c|c|}
\hline $\begin{array}{c}\text { GenBank accession } \\
\text { number }\end{array}$ & Probe ID & $\begin{array}{l}\text { Sequence } \\
\text { description }\end{array}$ & $\begin{array}{c}\text { Homologous } \\
\text { species }\end{array}$ & $\begin{array}{l}\text { Minimum E- } \\
\text { value }\end{array}$ & $\begin{array}{c}\text { Fold change (fed } P \text {. ovis vs } \\
\text { starved } P \text {. ovis) }\end{array}$ & $\begin{array}{c}\text { FDR corrected } \\
\mathrm{p} \text {-value }\end{array}$ \\
\hline FR748349 & $\mathrm{Bu}$-002_g12 & - & - & - & 1.55 & 0.0017 \\
\hline FR748466 & Bu_004_b02 & Beta-1,3-D-glucanase & $\begin{array}{l}\text { Cryptopygus } \\
\text { antarcticus }\end{array}$ & $8.82 \mathrm{E}-22$ & 2.32 & 0.00002 \\
\hline FR748550 & Bu_005_a09 & - & - & - & 2.47 & 0.002 \\
\hline FR748633 & Bu_005_h12 & $\begin{array}{l}\text { Pso o } 1 / \text { Der } \mathrm{p} 1 \\
\text { allergen }\end{array}$ & $\begin{array}{l}\text { P. ovis/D. } \\
\text { pteronyssinus }\end{array}$ & $2.36 \mathrm{E}-46$ & 2.17 & 0.00001 \\
\hline FR748686 & Bu_006_e09 & $\begin{array}{c}\text { Macrolide } \\
\text { glycosyltransferase }\end{array}$ & $\begin{array}{l}\text { Streptosporangium } \\
\text { roseum }\end{array}$ & 1.49E-44 & 1.95 & 0.00002 \\
\hline FR748740 & Bu_007_b11 & Der p 21 allergen & D. farinae & $2.13 \mathrm{E}-36$ & 1.82 & 0.0002 \\
\hline- & Bu_007_e02 & - & - & - & 1.51 & 0.0002 \\
\hline FR748952 & Bu_010_f10 & Myosin light chain & $\begin{array}{l}\text { Haemaphysalis } \\
\text { qinghaiensis }\end{array}$ & $3.26 \mathrm{E}-57$ & 1.53 & 0.0029 \\
\hline FR749449 & Bu_017_f04 & $\begin{array}{l}\text { Pso o } 2 \text { group } 2 \\
\text { allergen }\end{array}$ & P. ovis & $1.49 E-53$ & 2.15 & 0.0025 \\
\hline
\end{tabular}

Probe ID represents the unique identifier for the microarray probe. FDR corrected p-value shows the Benjamini \& Hochberg False Discovery Rate (FDR) corrected p-value for each transcript [23]. E-value is the Expect value which describes the number of BLAST hits one can expect to see by chance for a given sequence, the lower the E-value the more significant the match.

Table 2 Top 20 transcripts significantly up-regulated in the starved P.ovis mite sample.

\begin{tabular}{|c|c|c|c|c|c|c|}
\hline $\begin{array}{c}\text { GenBank } \\
\text { accession number }\end{array}$ & Probe ID & Sequence description & $\begin{array}{l}\text { Homologous } \\
\text { species }\end{array}$ & $\begin{array}{l}\text { Minimum } \\
\text { E-value }\end{array}$ & $\begin{array}{l}\text { Fold change (starved } P \text {. ovis } \\
\text { vs fed } P \text {. ovis) }\end{array}$ & $\begin{array}{l}\text { FDR corrected } \\
p \text {-value }\end{array}$ \\
\hline FR748352 & Bu_002_h03 & $\begin{array}{l}\text { Calcium-independent } \\
\text { phospholipase A2-gamma }\end{array}$ & $\begin{array}{l}\text { Tribolium } \\
\text { castaneum }\end{array}$ & $1.6 \mathrm{E}-49$ & 2.68 & 1.45E-05 \\
\hline FR749255 & Bu_015_c09 & $\begin{array}{l}\text { Heat shock protein HSP90- } \\
\text { alpha }\end{array}$ & $\begin{array}{l}\text { Ixodes } \\
\text { scapularis }\end{array}$ & $5.67 \mathrm{E}-77$ & 2.66 & 0.015 \\
\hline- & $\mathrm{Bu} 016 \_f 12$ & - & - & - & 2.61 & 1.93E-05 \\
\hline FR749314 & Bu_016_a06 & Lipase, family member KJJ & Pan troglodytes & $2.93 E-37$ & 2.56 & $2.62 \mathrm{E}-07$ \\
\hline FR749136 & Bu_013_g02 & Ras-related GTP binding A & I. scapularis & $6.02 \mathrm{E}-46$ & 2.5 & 2.79E-05 \\
\hline FR748742 & Bu_007_c01 & $A B C$ transporter & I. scapularis & $6.48 \mathrm{E}-62$ & 2.47 & $1.54 \mathrm{E}-05$ \\
\hline FR748556 & Bu_005_b04 & - & - & - & 2.46 & 1.49E-05 \\
\hline- & Bu_014_d11 & - & - & - & 2.44 & 0.002635 \\
\hline FR749256 & Bu_015_c10 & $\begin{array}{c}\text { Solute carrier family } 27 \text { (fatty } \\
\text { acid transporter) }\end{array}$ & $\begin{array}{c}\text { Nasonia } \\
\text { vitripennis }\end{array}$ & $4.01 E-40$ & 2.43 & 0.00018 \\
\hline FR749382 & Bu_016_h02 & $\begin{array}{l}\text { RNA-binding protein MEX3C- } \\
\text { like }\end{array}$ & Drosophila virilis & 0.00016 & 2.42 & 2.59E-08 \\
\hline FR749562 & Bu_011_a04 & Tubulin beta-4 chain-like & $\begin{array}{c}\text { Caernorhabditis } \\
\text { briggsae }\end{array}$ & $1.46 \mathrm{E}-24$ & 2.41 & $8.22 \mathrm{E}-05$ \\
\hline FR748807 & Bu_009_a04 & Polo-like kinase 3 & $\begin{array}{l}\text { Nematostella } \\
\text { vectensis }\end{array}$ & $5.49 \mathrm{E}-16$ & 2.39 & 0.005 \\
\hline FR749241 & Bu_015_b06 & $\begin{array}{l}\text { MAD2 mitotic arrest deficient- } \\
\text { like } 1\end{array}$ & $\begin{array}{l}\text { Branchiostoma } \\
\text { floridae }\end{array}$ & 4.09E-50 & 2.39 & 8.73E-05 \\
\hline FR749251 & Bu_015_c05 & Replication factor C subunit 5 & $\begin{array}{l}\text { Acyrthosiphon } \\
\text { pisum }\end{array}$ & $1.49 \mathrm{E}-89$ & 2.39 & 0.0001 \\
\hline FR749291 & $\mathrm{Bu}$ _015_f12 & $\begin{array}{l}\text { Sporozoite asparagine-rich } \\
\text { protein }\end{array}$ & $\begin{array}{l}\text { Plasmodium } \\
\text { falciparum }\end{array}$ & $4 \mathrm{E}-04$ & 2.36 & 0.0016 \\
\hline FR748903 & Bu_010_b08 & Exosome component 7 & 1. scapularis & $6.59 \mathrm{E}-41$ & 2.33 & 0.001273 \\
\hline FR748544 & Bu_005_a03 & - & - & - & 2.32 & $3.73 \mathrm{E}-08$ \\
\hline FR749434 & $\mathrm{Bu}$-017_d11 & $\begin{array}{l}\text { Hydroxysteroid (17-beta) } \\
\text { dehydrogenase }\end{array}$ & 1. scapularis & $1.77 \mathrm{E}-13$ & 2.3 & 0.000138 \\
\hline FR749176 & Bu_014_c08 & - & - & - & 2.29 & 0.000162 \\
\hline FR749632 & Bu_011_g07 & $\begin{array}{l}\text { Ankyrin repeat domain- } \\
\text { containing protein } 49\end{array}$ & $\begin{array}{l}\text { Saccoglossus } \\
\text { kowalevskii }\end{array}$ & $2.52 \mathrm{E}-32$ & 2.29 & 0.004882 \\
\hline
\end{tabular}

Probe ID represents the unique identifier for the microarray probe. FDR corrected p-value shows the Benjamini \& Hochberg False Discovery Rate (FDR) corrected p-value for each transcript [23]. E-value is the Expect value which describes the number of BLAST hits one can expect to see by chance for a given sequence, the lower the E-value the more significant the match. 
approach, based on an understanding of: i) which molecules are essential to survival, and ii) the accessibility of these molecules to the host immune system, has been advocated in the field of ectoparasite vaccine development for several years [25]. Thus far, for P. ovis, candidate antigens have been identified through either a "pragmatic" approach of fractionating native protein extracts of the mites and using these as vaccines $[15,16]$, or by immunoscreening cDNA libraries [18]. The use of a $P$. ovis microarray represents an alternative approach, by targeting those molecules which are differentially regulated during, for example, feeding we can start to address the first of the criteria for rational selection.

The genes up-regulated in the fed mites included homologues of the well characterised HDM allergens Der p 1 and Der p 2, namely Pso o 1 and Pso o 2. Both factors are known to be expressed in the mite gut and are hypothesised to play key roles in mite digestive processes [26,27]. In further support of these findings a previous study using the method of suppressive subtractive hybridisation demonstrated the up-regulation of Pso o 1 in fed $v s$ starved P. ovis mites [28]. Pso o 2 is a homologue of the HDM allergen Der p 2 which has been shown to act as a functional mimic of the toll-like receptor 4 (TLR4) accessory protein; MD-2 [29]. Der $\mathrm{p}$ 2 has also been localised to mite gut and faecal pellets and may also be involved in the triggering of the cutaneous inflammatory response upon which the mites feed $[8,9]$. The allergen Der p 21 (Pso o 21 in P. ovis) has also been localised to HDM gut and faecal pellets and may have a role in mite feeding [30] and up-regulation of this transcript in fed $P$. ovis mites may be indicative of active digestion. These allergens have previously been localised to HDM faecal pellets and their homologues in $P$. ovis are therefore likely to come into contact with host skin $[26,27,30]$. During infestation, P. ovis does not penetrate beyond the stratum corneum and the host cutaneous inflammatory response appears to be triggered by the presence of proteolytic enzymes, such as Pso o 1 . The observation that these allergens are recognised by the host immune response following infestation suggests they may be valid targets for immunisation $[26,30]$.

Amongst the transcripts up-regulated in starved mites were a number representing genes involved in the stress response, including those implicated in the cellular response to heat shock. Heat shock proteins are molecular chaperones with key roles in signal transduction, protein folding and degradation and can also be upregulated as part of the stress response to starvation [31,32]. Homologues of two tick genes involved in autophagy were also up-regulated in starved $P$. ovis mites, namely ATG3 and DRAM1. The process of autophagy is a critical proteolysis system that is induced during starvation [33]. Although the $P$. ovis life cycle takes place in its entirety on the host, the mites are able to survive off-host for up 15-16 days and they, like other arthropods, must therefore possess a degree of tolerance to starvation $[4,10]$. In ticks the process of autophagy helps to compensate for the lack of host-derived nutrients during periods of time spent off-host [34,35]. The identification of genes potentially involved in autophagy indicates that a similar process may also exist in $P$. ovis, thus protecting mites during periods spent off-host and allowing mites to survive during transfer from one host to the next. Also of note was the 2-fold up-regulation of a homologue of the receptor (chemosensory) transporting protein from I. scapularis and receptor accessory protein 4 from Caenorhabditis briggsae in starved $P$. ovis mites. These factors have been implicated in the promotion of the functional cell surface expression of odorant receptors [36] which play key roles in the detection of odour and in the location of the host or a preferred food source [37]. The up-regulation of these factors in starved mites may be indicative of the mite response to a lack of nutrients by increasing efforts to locate a food source. This is further supported by the previous identification of an olfactory receptor up-regulated in starved $P$. ovis mites [28]. Also up-regulated in starved mites were two probes representing homologues of I. scapularis secreted salivary factors (a secreted salivary gland peptide (2-fold) and a secreted salivary protein (1.6-fold)). Although salivary gland structures have not been conclusively identified in $P$. ovis they are present in other Astigmatid mites e.g. Acarus siro [38]. In addition four homologues of potential salivary/oesophageal gland factors have been identified in P. ovis, although in this study these factors were up-regulated in fed mites [28]. The up-regulation of salivary factors in starved mites as described here may be indicative of increased preparation to feed and the observed contradiction in regulation between this and the previous study [28], is likely to be due to the identification of different factors in each study.

\section{Conclusions}

Through the analysis described in this study, the $P$. ovis array has been shown to be robust and more importantly to provide highly reproducible results. Although the emerging technologies of next generation sequencing and digital transcriptomic analysis are set to transform this type of analysis in the future, they currently require the presence of a genome or transcriptome upon which to map digital sequence reads. In addition, each separate comparison requires that an entirely new analysis be performed, meaning that the cost is replicated on each occasion. In contrast, the array described here enables multiple comparisons to be made for a 
relatively low cost, i.e. the nominal cost of a printed slide and reagents. The $P$. ovis array provides an excellent resource for the transcriptomic analysis of $P$. ovis and related mites and opens up the possibility of future studies to dissect as yet unexplored aspects of mite virulence [39], the increasing problem of drug resistance $[40,41]$ and the transcriptional analysis of different life cycles stages, i.e. egg, larva, nymphal stages and adults. The $P$. ovis cDNA array is available from the authors upon request.

\section{Additional material}

Additional file 1: $P$. ovis CDNA microarray annotation data. This file contains the annotation of the probes used in the construction of the $P$. ovis CDNA microarray, which includes Probe ID, GenBank accession ID and sequence description from BLAST analysis.

Additional file 2: Microarray transcripts up-regulated in starved $P$. ovis mites. This file contains the full list of 675 probes found to be significantly up-regulated in starved $P$. ovis mites and contains the Probe ID, GenBank accession ID, sequence description, minimum E-value, fold change and FDR corrected $\mathrm{p}$-value for each probe.

\section{Acknowledgements}

This study was funded by the Department for Environment, Food and Rural Affairs (Defra), UK under project OD0553. CAW, FK, JFH and AJN gratefully acknowledge funding from the Scottish Government. We would like to thank Richard Talbot of the ARK Genomics Centre for Comparative and Functional Genomics for his invaluable technical advice; Alex Lainson and Raja Yaga of the Moredun Bioinformatics Division for their bioinformatics support and BLAST analysis and the Moredun Clinical Division for their continued help and expertise in animal care.

\section{Author details}

${ }^{1}$ Moredun Research Institute, Pentlands Science Park, Bush Loan, Edinburgh Midlothian. EH26 OPZ. UK. ${ }^{2}$ ARK-Genomics, The Roslin Institute, University of Edinburgh, Roslin. Midlothian. EH25 9PS, UK. ${ }^{3}$ Strathclyde Institute of Pharmacy and Biomedical Sciences, University of Strathclyde, 161 Cathedral Street, Glasgow. G4 ORE. UK.

\section{Authors' contributions}

STGB designed the study, performed and processed mite samples and RNA extractions, participated in the design and annotation of the microarray, analysed the microarray and $\mathrm{qPCR}$ data and wrote the manuscript. AD participated in the study design, constructed the P. ovis microarray, processed the samples and microarray hybridisations and analysed the microarray data. CAW participated in the microarray design, annotation and EBI submission of sequence and microarray data and helped to prepare the manuscript. EJM performed and analysed the GPCR comparisons. AJN participated in the study design and data analysis and helped to prepare the manuscript. FK provided access to $P$. ovis expressed sequence tags and assisted with data analysis and manuscript preparation. CM assisted with data analysis and manuscript preparation and supplied sequence data and constructs for Pso o 1 and Pso o 2. JFH conceived and designed the study and helped to prepare the manuscript. All authors have read and approved the manuscript.

\section{Competing interests}

The authors declare that they have no competing interests.

Received: 30 November 2011 Accepted: 8 February 2012 Published: 8 February 2012
References

1. Kirkwood AC: History, biology and control of sheep scab. Parasitol Today 1986, 2:302-307.

2. Nieuwhof GJ, Bishop SC: Costs of the major endemic diseases of sheep in Great Britain and the potential benefits of reduction in disease impact. Animal Science 2005, 81:23-29.

3. Nisbet AJ, Huntley JF: Progress and opportunities in the development of vaccines against mites, fleas and myiasis-causing flies of veterinary importance. Parasite Immunol 2006, 28:165-172.

4. Sweatman GK: Biology of Otodectes cynotis, the ear canker mite of carnivores. Candian Journal of Zoology 1958, 36:849-862.

5. O'Brien DJ, Gray JS, O'Reilly PF: Examination of possible transmission of sheep scab mite Psoroptes ovis between host species. Vet Res Commun 1994, 18:113-117.

6. DeLoach JR, Wright FC: Ingestion of rabbit erythrocytes containing $51 \mathrm{Cr}$ labeled hemoglobin by Psoroptes spp. (Acari: Psoroptidae) that originated on cattle, mountain sheep, or rabbits. J Med Entomol 1981, 18:345-348.

7. Mathieson BR, Lehane MJ: Ultrastructure of the alimentary canal of the sheep scab mite, Psoroptes ovis (Acari: Psoroptidae). Vet Parasitol 2002, 104:151-166.

8. Burgess ST, Frew D, Nunn F, Watkins CA, McNeilly TN, Nisbet AJ, Huntley JF: Transcriptomic analysis of the temporal host response to skin infestation with the ectoparasitic mite Psoroptes ovis. BMC Genomics 2010, 11:624.

9. van den Broek AH, Huntley JF: Sheep scab: the disease, pathogenesis and control. J Comp Pathol 2003, 128:79-91.

10. Hamilton KA, Nisbet AJ, Lehane MJ, Taylor MA, Billingsley PF: A physiological and biochemical model for digestion in the ectoparasitic mite, Psoroptes ovis (Acari: Psoroptidae). Int J Parasitol 2003, 33:773-785.

11. Sinclair AN, Filan SJ: Confirmation of degenerative effects on psoroptic mites from scab lesions. Vet Rec 1991, 129:492.

12. Thomas WR, Smith W: House-dust-mite allergens. Allergy 1998, 53:821-832.

13. van den Broek AH, Else RW, Huntley JF, Machell J, Taylor MA, Miller HR: Early innate and longer-term adaptive cutaneous immunoinflammatory responses during primary infestation with the sheep scab mite, Psoroptes ovis. J Comp Pathol 2004, 131:318-329.

14. Bates P: Differences between primary and secondary infestations with the sheep scab mite, Psoroptes ovis. Vet Rec 2000, 146:528-529.

15. Smith WD, Bates P, Pettit DM, Van Den Broek A, Taylor MA: Attempts to immunize sheep against the scab mite, Psoroptes ovis. Parasite Immunol 2002, 24:303-310.

16. Smith WD, van den Broek A, Huntley J, Pettit D, Machell J, Miller HR, Bates $P$, Taylor M: Approaches to vaccines for Psoroptes ovis (sheep scab). Res Vet Sci 2001, 70:87-91.

17. Burgess STG, Nisbet AJ, Kenyon F, Huntley J: Generation, analysis and functional annotation of expressed sequence tags from the ectoparasitic mite Psoroptes ovis. Parasites \& Vectors 2011, 4:145.

18. Nisbet AJ, Halliday AM, Parker L, Smith WD, Kenyon F, Knox DP, Huntley JF: Psoroptes ovis: identification of vaccine candidates by immunoscreening. Exp Parasitol 2008, 120:194-199.

19. Altschul SF, Gish W, Miller W, Myers EW, Lipman DJ: Basic local alignment search tool. J Mol Biol 1990, 215:403-410.

20. Conesa A, Gotz S: Blast2GO: A comprehensive suite for functional analysis in plant genomics. Int J Plant Genomics 2008, 2008:619832

21. Conesa A, Gotz S, Garcia-Gomez JM, Terol J, Talon M, Robles M: Blast2GO: a universal tool for annotation, visualization and analysis in functional genomics research. Bioinformatics 2005, 21:3674-3676.

22. Gotz S, Garcia-Gomez JM, Terol J, Williams TD, Nagaraj SH, Nueda MJ, Robles M, Talon M, Dopazo J, Conesa A: High-throughput functional annotation and data mining with the Blast2GO suite. Nucleic Acids Res 2008, 36:3420-3435.

23. Benjamini Y, Hochberg Y: Controlling the false discovery rate: a practical and powerful approach to multiple testing. Journal of the Royal Statistical Society Series B 1995, 57:289-300.

24. The National Center for Biotechnology Information primer designing tool Primer3 and BLAST. [http://www.ebi.ac.uk/Tools/sequence.html].

25. Willadsen P: Anti-tick vaccines. Parasitology 2004, 129 Suppl:S367-387.

26. Nisbet AJ, MacKellar A, McLean K, Brennan GP, Huntley JF: Eukaryotic expression of recombinant Pso o 1, an allergen from Psoroptes ovis, and its localization in the mite. Parasitology 2007, 134:83-89. 
27. Kenyon F, Knox D: The proteinases of Psoroptes ovis, the sheep scab mite-their diversity and substrate specificity. Vet Parasitol 2002, 105:317-325.

28. MCNair CM, Billingsley PF, Nisbet AJ, Knox DP: Feeding-associated gene expression in sheep scab mites (Psoroptes ovis). Vet Res 2010, 41:16.

29. Trompette A, Divanovic S, Visintin A, Blanchard C, Hegde RS, Madan R, Thorne PS, Wills-Karp M, Gioannini TL, Weiss JP, Karp CL: Allergenicity resulting from functional mimicry of a Toll-like receptor complex protein. Nature 2009, 457:585-588.

30. Weghofer M, Dall'Antonia Y, Grote M, Stocklinger A, Kneidinger M, Balic N, Krauth MT, Fernandez-Caldas E, Thomas WR, van Hage M, Vieths S, Spitzauer S, Horak F, Svergun DI, Konarev PV, Valent P, Thalhamer J, Keller W, Valenta R, Vrtala S: Characterization of Der p 21, a new important allergen derived from the gut of house dust mites. Allergy 2008, 63:758-767.

31. Santoro MG: Heat shock factors and the control of the stress response. Biochem Pharmacol 2000, 59:55-63.

32. Cherkasova V, Ayyadevara S, Egilmez N, Shmookler Reis R: Diverse Caenorhabditis elegans genes that are upregulated in dauer larvae also show elevated transcript levels in long-lived, aged, or starved adults. J Mol Biol 2000, 300:433-448.

33. Yorimitsu T, Klionsky DJ: Autophagy: molecular machinery for self-eating. Cell Death Differ 2005, 12(Suppl 2):1542-1552.

34. Umemiya-Shirafuji R, Matsuo T, Fujisaki K: Autophagy in ticks. Methods Enzymol 2008, 451:621-638

35. Umemiya R, Matsuo T, Hatta T, Sakakibara S, Boldbaatar D, Fujisaki K Autophagy-related genes from a tick, Haemaphysalis longicornis. Autophagy 2008, 4:79-81.

36. Matsunami H, Mainland JD, Dey S: Trafficking of mammalian chemosensory receptors by receptor-transporting proteins. Ann N Y Acad Sci 2009, 1170:153-156.

37. Dahanukar A, Hallem EA, Carlson JR: Insect chemoreception. Curr Opin Neurobiol 2005, 15:423-430

38. Hughes TE: The Physiology of the Alimentary Canal of Tyroglyphus farinae. Journal of Microscopical Science 1950, s3-91:45-61.

39. Bates PG: Inter- and intra-specific variation within the genus Psoroptes (Acari: Psoroptidae). Vet Parasitol 1999, 83:201-217.

40. Pap L, Sarkozy P, Farkas R, Bleicher E, Szego A: Efficacy of some pyrethroids against a strain of the rabbit ear mite (Psoroptes cuniculi): an unusual cross-resistance pattern. Parasitol Res 1997, 83:203-205.

41. Clark AM, Stephen FB, Cawley GD, Bellworthy SJ, Groves BA: Resistance of the sheep scab mite Psoroptes ovis to propetamphos. Vet Rec 1996 139:451.

doi:10.1186/1756-3305-5-30

Cite this article as: Burgess et al:: Development of a cDNA microarray for the measurement of gene expression in the sheep scab mite Psoroptes ovis. Parasites \& Vectors 2012 5:30.

\section{Submit your next manuscript to BioMed Central and take full advantage of:}

- Convenient online submission

- Thorough peer review

- No space constraints or color figure charges

- Immediate publication on acceptance

- Inclusion in PubMed, CAS, Scopus and Google Scholar

- Research which is freely available for redistribution

Submit your manuscript at www.biomedcentral.com/submit
Biomed Central 